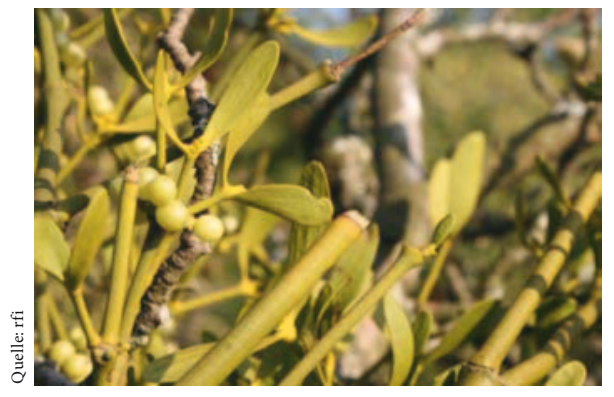

Die Bekämpfung der Mangelernährung spielt in der Krebstherapie eine wichtige Rolle. Eine schlechte Versorgung ist eine der häufigsten Komplikationen einer Tumorerkrankung, die zum Tode des Patienten führen. Deutlich wird dies am Gewichtsverlauf von Krebspatienten: Bei der Diagnose haben bereits $50 \%$ an Gewicht verloren. Ein Fünftel hat innerhalb eines halben Jahres 10\% des Ausgangsgewichts eingebüsst. Nach den Ergebnissen einer Untersuchung waren fast $40 \%$ der Tumorpatienten in deutschen Krankenhäusern nicht ausreichend ernährt. Nicht nur der Tumor selbst absorbiert einen grossen Teil der Energie, zur Mangelernährung traten auch Appetitlosigkeit, Nebenwirkungen der Therapie und hormon- und zytokinbedingte Stoffwechselstörungen hinzu.

Von einer Reihe von Mikronährstoffen, wie z.B. Glutamin, Arginin, Cystein, Selen, Zink oder Vitamin A, $\mathrm{C}$ und $\mathrm{E}$, ist bekannt, dass sie das Immunsystem von Krebspatienten stabilisieren helfen. Das gilt sowohl für das durch die Krebserkrankung selbst als auch durch die Behandlung des Tumors in Mitleidenschaft gezogene Abwehrsystem. Besonders von Cystein und Glutamin können Patienten profitieren, deren Muskelmasse im Zuge der Erkrankung abgenommen hat. Die beiden Moleküle sind für den Erhalt von Muskelzellen erforderlich sie können helfen, dem Verlust von Eiweiss vorzubeugen.

Vor Beginn einer Therapie mit Mikronährstoffen sollte die aktuelle

\title{
Mikronährstoffe in der Onkologie
}

In den letzten Jahren hat die Bedeutung von Mikronährstoffen stark zugenommen. Bei der Prävention von Krebs können sie eine unterstützende Rolle spielen.

Versorgungssituation des Patienten durch eine Mikronährstoffanalyse des Bluts bestimmt werden. Nur so kann eine adäquate Behandlung sichergestellt werden. Während es unbestritten ist, dass viele Mikronährstoffe zu einer Verbesserung des Wohlbefindens der Patienten führen, dürfen sie bei einer Krebstherapie allerdings nicht willkürlich angewendet werden. Die Gefahr von Wechselwirkungen mit Krebsmedikamenten, die während einer Strahlen- oder Chemotherapie verabreicht werden, ist zu gross. Es gibt präklinische und auch erste klinische Daten, die zeigen, dass der Erfolg der Anti-Tumortherapie durch Mikronährstoffe, insbesondere durch Antioxidantien, gefährdet werden kann. Deshalb sollten insbesondere Mikronährstoffe mit komplexer Molekularstruktur im Zweifelsfall nicht angewendet werden. Das Risiko von unvorhergesehenen Wechselwirkungen ist zu gross.

Der Körper ist auf die Versorgung mit Mikronährstoffen von aussen angewiesen, da er sie nicht selbst bilden kann. Zu den Mikronährstoffen gehören Vitamine, Mineralien und Spurenelemente, deren wichtige Aufgabe es ist, die molekularen Prozesse bei der Reparatur und Instandhaltung der DNA zu unterstützen. Wird die DNA bei diesem Prozess beschädigt, kann das Zellwachstum bei weiteren Mitosen ausser Kontrolle geraten und Krebs entstehen. Ein verbesserter Schutz der DNA durch eine ausreichende Versorgung des Organismus mit Mikronährstoffen kann dazu beitragen, Krebserkrankungen zu verhindern.
Die ausreichende Versorgung mit Mikronährstoffen soll vor allem den oxidativen Stress reduzieren, dem der Körper durch freie Radikale ausgesetzt ist. Diese Moleküle, die während des Stoffwechsels entstehen, greifen durch ihre Oxidationswirkung z.B. die DNA an und zerstören sie. Der Körper verfügt über eigene antioxidative Schutzsysteme, die allerdings nicht ausreichen. Der primäre antioxidative Schutz bedient sich des Scavenger-Enzymsystems, des Glutathion-Systems und verschiedener Antioxidantien. Das Scavenger-Enzymsystem besteht aus einer Reihe von verschiedenen Enzymen, die die freien Radikale «einfangen». Zu ihnen gehören die Superoxid-Dismutase, die Katalase, die Glutathion-Peroxidase, -Reduktase und -S-Transferase sowie die Glucose-6-Phosphat-Dehydrogenase. Für ihre Wirkung ist das Vorhandensein von beispielsweise Kupfer, Eisen, Mangan, Zink oder Selen als Kofaktoren notwendig.

Eine wichtige Rolle spielt das Glutathion-System. Es gibt bereits über 6000 wissenschaftliche Untersuchungen, die sich mit seiner Wirkung zum Schutz vor freien Radikalen beschäftigt. Glutathion ist ein Tripeptid, das aus Glutamin, Glycin und Cystein besteht. Das System neutralisiert reaktive Sauerstoffverbindungen wie etwa Wasserstoffperoxid und organische Hydroperoxide. So schützt es Zellen, DNA, Lipide, Membranen und Mitochondrien vor der Oxidation. Bei der Neutralisation wird es selbst oxidiert und später durch eine Reduktase wieder regeneriert. $(r f i)$

\section{KARGER}

Fax +497614520714 